\title{
Reflections on the challenges and possibilities of journal publication in science education
}

\author{
Catherine Milne ${ }^{1} \cdot$ Christina Siry $^{2} \cdot$ Michael Mueller $^{3}$
}

Received: 30 October 2015/Accepted: 30 October 2015/Published online: 27 November 2015

(C) Springer Science+Business Media Dordrecht 2015

\begin{abstract}
In this editorial we reflect on the intersections between the review and publishing policies of Cultural Studies of Science Education (CSSE) and the challenges and possibilities in global science education publishing. In particular we discuss the tensions associated with open or closed review policies, the hegemony of English as a language of publication, and reflect on some of the common challenges experienced by editors and authors from different contexts. We draw on the paper set in this issue consisting of five papers focused on publishing in various contexts, and elaborate several central questions for the field of science education and the dissemination of knowledges.
\end{abstract}

Keywords Publishing policies - English hegemony - Cultural studies - Review process · Research methods

Launched in 2006, Cultural Studies of Science Education (CSSE) is a journal that was founded in part to address the question of how research journals can better serve the needs of the science education field while also serving the diverse stakeholders that participate in that field. One answer to this question was the establishment of a journal with the goal, in its broadest sense, of supporting the publication of scholarly articles that employ social and

Lead Editor: C. Siry.

This editorial responds and expands the dialogue initiated by a paper set including original manuscripts by Mariona Espinet, Merce Izquierdo and Carla Garcia-Pujol (2015); Ludovic Morge; and Isabel Martins and Susana De Souza Barros (2015) and forum papers by Carolina Castano Rodriguez (2015) and Yew-Jin Lee (2015).

\footnotetext{
Catherine Milne

catherine.milne@nyu.edu

New York, NY, USA

2 Luxembourg City, Luxembourg

3 Anchorage, AK, USA
} 
cultural perspectives as the basis for scholarly activities within science education and associated fields (see Roth and Tobin 2006). Founded by Kenneth Tobin and Wolff-Michael Roth, and published by Springer, its mission is to be an international journal for the interdisciplinary study of knowing and learning in science. Consequently, the journal encourages both empirical and non-empirical approaches that are implemented in formal and informal sites of educational production, or across the life-long spectrum of learning in science education. Evidence of its commitment to publishing manuscripts that use different theoretical lenses to explore varied elements of what constitutes science education can be found in the publication of one of the paper sets in this issue, consisting of five papers in total, including three original manuscripts (Espinet, Izquierdo \& Garcia-Puiol; Martins \& de Souza Barros; Morge) and two Forum papers (Castano Rodriguez; Lee) that focus on a variety of themes related to journal publishing internationally. In this editorial, we, the current co-editors-in-chief of CSSE, take this paper set as a whole, and use the points raised across the papers as points of discussion for our own perspectives for CSSE. We begin with situating CSSE in the conversations elaborated in the paper set, and then address some of the key questions that have been central to our editorial work and the evolution of CSSE through the years.

Confirming the role of professional journals for legitimizing research, Isabel Martins and Susana de Souza Barros note in their manuscript, The Role of Journals in Building Up Communities: The Experience of Ciência em Tela:

The role of journals is vital not only for the dissemination but also for the validation and legitimation of research related ideas and outcomes. However, as instruments that operate within social practices, publications, in general, congregate groups who share concerns and practices and who play similar social roles.

We agree that journals give voice to groups, validating and disseminating ideas and research that are representative of a collective perspective, certainly the rationale for the establishment of CSSE! But this paper set does more than provide justification for the continued existence of CSSE, it also explores some of the challenges and responsibilities associated with journals in the global climate of manuscript publishing. The authors of these papers highlight the general nature of some of the challenges that CSSE has wrestled with as it also contributes to a dynamic milieu in which authors and readers participate in the production of new forms of scholarship and new identities for educational research and practice. We thus take this paper set as a whole, and in the sections that follow explore some of the questions raised in order to address these challenges and possibilities from our lenses as the co-editors of CSSE.

\section{So what are these challenges?}

Some of the challenges of journal publication can be listed as questions that are a focus of our thinking in CSSE and which also inform the perspectives of the papers in this paper set: What do emphases on sociocultural perspectives on science and science education ask of authors and readers? How can the process of scholarly (or "peer") review and mentorship be considered part of the research conversation? How do we ensure that other publication models, beyond neoliberal tenets, have a place and space in review and publication? How do we build bridges between different theoretical/discipline-based perspectives of how knowledge should be constructed while also working to ensure that multiplicities of voices have the opportunity to be presented and heard? 


\section{What do emphases on sociocultural perspectives on science education ask of authors and readers?}

Sociocultural perspectives situate science education research as a social, cultural act. As such, an overarching focus as a journal on the cultural studies of science education implies a necessary valuing of multiple perspectives in examining science education and associated disciplines, as these are situated in a praxis of culture and the social elements that construct and constrain that cultural praxis. These multiple perspectives add complexity and intrigue in exploring questions of epistemology, ontology and axiology that tend to be the focus of research in the discipline of science education and interwoven disciplines. Evoking a sociocultural paradigm means thinking deeply about the relationships between issues such as power and knowledge, power and privilege, and power and identity in the construction of research narratives and arguments. It means authors showing how theoretical and social constructs like age, identity, race, gender, capital, place, and reflexivity are understood and used in their research. It means that researchers using instruments like surveys and interviews are expected to show what theoretical and empirical perspectives informed the development of each instrument and its attendant items. It means moving away from simplistic empirical studies that make only passing reference to the author's theoretical biases. It means finding a place for creative approaches to the conduct of research and data generation but it also means doing this by sidelining our limitations. In an editorial for the CSSE Special Issue on conceptual change and sociocultural perspectives Tobin (2008) wrote:

I have continuously searched for appropriate theoretical frameworks for my research in science education, being mindful of Max Van Manen's (1990) advice that those seeking to shine fresh light on an issue first must find the light. In so doing I have been mindful that as theories illuminate landscapes in particular ways, they simultaneously obscure or fail to discern other potentially salient issues. (p. 227)

So the issue is not just to acknowledge one's theoretical positions but also to acknowledge, as Kenneth Gergen (1994) notes, that a focus on one perspective or a move from interchange to a single continuum flattens the world and silences other voices (see also Milne 2009). In CSSE we have worked to support authors to take multiple perspectives that offer the possibility of opening up their analysis and thereby presenting a more nuanced perspective on a problem or issue. The production and dissemination of a praxis of knowledge in our fields are shaped by various historical, political, economic, and cultural forces at play in any given context. Sociocultural influences to publication of a journal allow for these voices to be highlighted, yet also require an awareness of the ways in which these different perspectives only each shine a light on some aspects while potentially obscuring others, as Tobin addresses in the quote above. As such, the open review process that CSSE holds as central becomes an important part to considering the complexities of research that is often locally contextualized yet internationally relevant.

\section{How can review be part of the research conversation?}

The model of review adopted at CSSE seeks to have the review process be a transparent one, in an effort to support the dissemination of research as one part of the interaction between authors, editors, and the field at large. We take the position that if our goal is to support critical colleagueship (Lord 1994) in a way that is respectful of all participants, there ought to be an ongoing dialogue that takes place between submitting authors, Lead 
Editors, Editors-in-Chief, and reviewers. This dialogue begins with the submission of a manuscript, and is a double-open process (versus double-blind), meaning that all participants in the review process dialogue are aware of who the others are, which requires a dedication to providing feedback with integrity and courage. The open review is a process that the journal has subscribed to since its inception with the founding editors, and now the current editorial team, being committed to a transparent process that seeks to be a more rigorous and more ethical process. Closed peer-review has been suggested to allude to a Kafka-esque world, whereas an open-review process can draw connections between the power and responsibility of the review process (Smith 1999). In the process of manuscript submission to CSSE, the authors and Lead Editor engage in an open dialogue about the substance of the article as the editors make the initial decision of whether the manuscript focus is consistent with the mission of CSSE. The two Forum papers in this paper set are good examples of how CSSE is working to support writers and scholars seeking to infuse science education research with more nuanced models of how one might conduct social science research beyond the simplistic models based on an ideology that equates anonymity with objectivity and scholarship. However in his paper, A Qualitative Analysis of the Determinants in the Choice of a French Journal Reviewing Procedures, Ludovic Morge, also a chief editor, provides a counterpoint to the CSSE position with respect to the reviewing of manuscripts. He explores the challenges facing a new journal, Recherches en Didactique des Sciences et des Technologies (RDST), which was formed from the merging of two science and technology education French language journals, Aster and Didaskalia. Although RDST faces some of the same challenges CSSE has faced, their potential reviewer pool initiated different decisions about how reviewing should be conducted. Clearly there are numerous possibilities for a journal to consider regarding their review policies, and for CSSE, we situate this as a dialogue with a goal of producing high quality manuscripts. As Roth and Tobin (2006) note, the role of reviewers is not to decide on acceptance or rejection of the manuscript but "to undertake scholarly critiques of manuscripts and provide perspectives that are salient to the production of improved manuscripts and an associated dialogue that reflects many forms of diversity (e.g., participation, perspective, methodology)" (p. 3). This dialogic review process is intended to support an openness for different types of review rather than a prescribed one-right way, and also a deepening of the "opportunities for teasing out debates" (McKinley and Gan 2014, p. 287), and by applying this strategy move us to more a much more detailed understanding of the fidelity of the act of engaging in the dissemination of science education research and practice.

\section{How do we ensure that diverse publication models have a place and space in review and publication?}

One of the foci for publications in CSSE is to work towards including publication models that push against neoliberal tenets, in order to ensure a multiplicity of perspectives and genres of publication. In addition to the open dialogue that begins with the submission of a manuscript, we conceive of publishing a manuscript as the start of a iterative conversation, as we utilize an approach in which many of the original papers in CSSE are positioned as a paper set, that is, they have other manuscripts written to build upon the points of the original paper and which continue the conversation with the designation of a "Forum" paper. We also see these conversations appear as "Op-Ed" articles as well, when printed later on. This approach allows the dialogue to occur in response to a manuscript, and is what we find with this paper set as Yew-Jin Lee, In a different voice; promises and trials of 
non-English speaking journals, and Carolina Castano Rodriguez, The dilemma of inclusivity in the globalization of academia, opt in their Forum papers to extend the conversations initiated by the original manuscripts. As Editor-in-Chief of another international journal, Pedagogies, Lee brings a unique perspective to the issue of English as the selected language for international publications in science education. The elevated status of English language hegemony in our field (e.g., Martin and Siry 2011) is a problem for CSSE and other journals, and as such in CSSE we encourage authors to publish extended summaries of their accepted papers in languages other than English. This "executive summary" is used by CSSE to extend the range of an author's work to other researchers who might not be working with English as their primary language, and we hope that it also extends the international reach of the work that is being done in our field. The issue of language in- and ex-clusivity is addressed in the contribution to this paper set by Mariona Espinet, Merce Izquierdo, and Clara Garcia-Pujol, as they detail the evolution of the journal Ensenanza de las Ciencias. Through the analysis of the processes of responding to globalization with internationalization, they discuss tensions that arise in working towards locally contextualized work that is also internationally relevant, and they reflect upon considerations for journals in being agents of cultural exchange, in particular the role of English language dominance. As a self-described early career researcher from an underrepresented language and culture, Rodriguez expands the conversation beyond the challenges of creating science education communities that involve teachers and researchers (see also Martins and de Souza Barros this issue) to explore the power structures within academe that hinder and undermine efforts to build community between university researchers and schools.

\section{How do we build bridges between different theoretical/discipline-based perspectives of how knowledge should be constructed while also working to ensure that multiplicities of voices have the opportunity to be presented and heard?}

All of the original papers in this set address the challenge of how to find a space for difference when globalization fosters a flat world where English is the language of communication in science and technology education research, withstanding most educational fields and some of the top educational journals such as those touted by the American Educational Research Association, for example. There is a huge tension here as CSSE is a journal that desires to share spaces with these other top journals while concomitantly standing for what scholars embrace and value about cultural studies.

Similar to some of the other journals that are the focus of study that CSSE encourages, authors are encouraged to submit lengthy summaries in languages other than English, as already mentioned above. While this is just a start, the requirement that scholars publish in English if they wish to advance in their field and the requirement that journals provide bibliographic information in English if they wish to be included in citation indexes reinforce English hegemony. CSSE has also worked to encourage a multiplicity of voices through the selection of Lead Editors and reviewers from as many countries as possible, and we seek to encourage authors from as many countries as possible to submit their work to the journal. The encouragement of a multiplicity of voices represents a more developed and progressive view than those that are inadvertently perpetuating a monovoice in science education (Mueller 2011). During these turbulent times, we need shared and dissident voices, and the constant reoccurring conversations that promote the plurality of perspectives that heighten our attention to the world. With the loss of dozens of languages worldwide annually, the loss of thousands of words associated with living well with other 
people and the lands, and the loss of a myriad traditions, ceremonies, skills, events, and narratives, CSSE strives to be the journal that stimulates growth in ordinary and extraordinary research venues and genres. For this reason, CSSE encourages philosophical, historical, sociological, phenomenological, and empirical qualitative and quantitative research in ways that are normally considered re/productive, including studies that are derived from the larger educational milieu outside of schools. CSSE publishes research that has dissolved the barriers between environmental and science education, beyond the psychometric and mandated assessments in school science that prioritize funding for some scholars and not others, and that expanded limited opportunities for tenure and promotion. By recognizing the merits of mainstream research, CSSE enlarged and is not limited by ordinary research, which includes essays, OP-ED, comment, criticism, letters, poetry, conference reviews, analyses of particular practices in science education, curriculum studies, and analyses of policy. We hope to foster the next generation of artisan researchers in cultural studies and science education, while maintaining a higher quality standard of review and integrated forum approach. It is because of these practices that CSSE will continue to work towards providing a place for the leading experts from around the world and provide a glimpse of what it is like to do research the world over; not compromised by one way of living in the world, one-age, one-culture, one-discipline, one-focus, but rather with a multitude of theoretical perspective and writing genres, and a multiplicity of different research perspectives and voices that represent the field of science education.

\section{References}

Castano Rodriguez, C. (2015). The dilemma of inclusivity in the globalization of academia. Cultural Studies of Science Education,. doi:10.1007/s11422-015-9691-7.

Espinet, M., Izquierdo, M., \& Garcia-Puiol, C. (2015). Can a Spanish science education journal become international? The case of Esenanza de las Ciencias. Cultural Studies of Science Education,. doi:10. 1007/s11422-013-9545-0.

Fitzsimons, P. (2000). Changing conceptions of globalization: Changing conceptions of education. Educational Theory, 50, 505-520.

Gergen, K. J. (1994). The limits of pure critique. In H. W. Simons \& M. Billig (Eds.), After postmodernism: Reconstructing ideology critique (pp. 58-78). London: Sage Publications.

Lee, Y.-J. (2015). In a different voice; promises and trials of non-English speaking journals. Cultural Studies of Science Education, doi:10.1007/s11422-015-9690-8.

Lord, B. (1994). Teachers' professional development: Critical colleagueship and the role of professional communities. In N. Cobb (Ed.), The future of education: Perspectives on national standards in America (pp. 175-204). New York: College Entrance Examination Board.

Martin, S. \& Siry, C. (2011). Networks of practice in science education research: A global context. Journal of Research in Science Education, 48, 592-623. doi:10.1002/tea.2025

Martins, I., \& de Souza Barros, S. (2015). The role of journals in building up communities: The experience of Ciência em Tela. Cultural Studies of Science Education,. doi:10.1007/s11422-014-9637-5.

McKinley, E., \& Gan, M. (2014). Culturally responsive science education for indigenous and ethnic minority students. In N. G. Lederman \& S. K. Abell (Eds.), Handbook of research on science education (Vol. II, pp. 284-300). New York: Taylor \& Francis.

Milne, C. (2009). Interpretive repertoires as mirrors on society and as tools for action: Reflections on Zeyer and Roth's A mirror on society. Cultural Studies of Science Education, 4, 1013-1022. doi:10.1007/ s11422-009-9237-y.

Morge, L. (2015). A qualitative analysis of the determinants in the choice of a French journal reviewing procedures. Cultural Studies of Science Education,. doi:10.1007/s11422-013-9549-9.

Mueller, M. P. (2011). Ecojustice in science education: Leaving the classroom. Cultural Studies of Science Education, 6, 351-360. doi:10.1007/s11422-011-9333-7.

Roth, W.-M., \& Tobin, K. (2006). Announcing Cultural Studies of Science Education. Cultural Studies of Science Education, 1, 1-5. doi:10.1007/s11422-005-9005-6. 
Smith, R. (1999). Opening up BMJ peer review: A beginning that should lead to complete transparency. British Medical Journal, 318(7175), 4-5.

Tobin, K. (2008). In search of new lights: Getting the most from competing perspectives. Cultural Studies of Science Education, 3, 227-230. doi:10.1007/s11422-008-9109-x.

Van Manen, M. (1990). Researching lived experience: Human science for action sensitive pedagogy. Albany, NY: State University of New York Press. 